\title{
Factors influencing the perception of medical staff and outpatients of dual practice in Shanghai, People's Republic of China
}

This article was published in the following Dove Press journal:

Patient Preference and Adherence

29 August 2016

Number of times this article has been viewed

\author{
Haiping Chen \\ Meina $\mathrm{Li}^{*}$ \\ Zhixin Dai* \\ Qiangyu Deng \\ Lulu Zhang
}

Department of Military Health Management, College of Health Service, Second Military Medical University, Shanghai, People's

Republic of China

*These authors contributed equally to this work
Correspondence: Lulu Zhang Department of Military Health Management, College of Health Service, Second Military Medical University, 800 Xiangyin Road, Yangpu District, Shanghai 200433, People's

Republic of China

Tel +86218187 I42I

Fax $+86218187 \mid 436$

Email zllrmit@aliyun.com
Objective: Dual practice is defined as a physician's performance of medical activities in different health care institutions (two or more) simultaneously. This study aimed to examine the perception and acceptance of medical staff and outpatients of dual practice and explore the possible factors affecting people's perception.

Methods: A cross-sectional study was conducted in 13 public hospitals in Shanghai. Participants included medical staff and outpatients. We distributed 1,000 questionnaires to each participant group, and the response rates were $66.7 \%$ and $69.4 \%$, respectively. Statistical differences in variables were tested, and multinomial logistic regression methods were employed for statistical analysis. Results: The study included two parts: medical staff survey and outpatient survey. The results of medical staff survey showed that $63.0 \%$ of the respondents supported dual practice. Medical staff who belonged to the surgical department or held positive belief of dual practice were more willing to participate in dual practice. Moreover, the publicity activities of dual practice and hospitals' human resource management system were important factors affecting the willingness of the medical staff. The results of outpatient survey showed that $44.5 \%$ of respondents believed that dual practice could reduce difficulty in consulting a doctor. Regarding the perceived benefits of dual practice, the proportion of outpatients who believed that dual practice could meet the demand for health convenience, minor illness, and chronic disease were $45.4 \%, 42.4 \%$, and $53.7 \%$, respectively. Additionally, demographic characteristics significantly influenced the perception of outpatients.

Conclusion: This study confirmed that both medical staff and outpatients generally held positive attitudes toward dual practice. Medical staff who belonged to the surgical department or held positive belief of dual practice were more willing to participate in dual practice. Moreover, the existence of publicity activities and more flexible management system of hospitals' human resource would promote physicians' willingness to participate in dual practice. In addition, perception of outpatients of dual practice was affected by demographic characteristics.

Keywords: dual practice, perception of medical staff, outpatients' perception, influential factors, labor supply

\section{Introduction}

To reduce the shortage and unreasonable distribution of health resources and address issues concerning insufficient outcome, low efficiency, and physicians' lassitude in public health institutions, health authorities in developed and developing countries have begun to adopt dual practice policy to improve health efficiency and allow more patients access to high-quality medical resources. ${ }^{1}$ Dual practice is defined as a physician's performance of medical activities in different health institutions (two or more) 
simultaneously. This can trigger a shift in human health care resources, causing disparity between urban and rural areas, public and private health institutions, and hospitals and community health institutions. ${ }^{1}$ Governments and health authorities usually use dual practice policy as a tool to offset the low income of medical staff and minimize health expenditure. Some scholars have posited that dual practice is a government behavior, which forces medical staff to work to ensure the safety of patients and private health institutions. ${ }^{2}$

Dual practice is used widely in health care systems in numerous European and Asian countries and exerts a direct or indirect impact on health labor supply, health care quality, waiting times, and health service expenditure. ${ }^{3,4}$ In the regions of Angola, Cambodia, Indonesia, Peru, Syria, and Vietnam, most doctors have dual practice in the public and private sectors. ${ }^{1,3,5}$ And both urban physicians and rural physicians join dual practice in Egypt and South Africa. ${ }^{3}$ Based on the premise of profit maximization for patients and health-related social cost minimization, government institutions formulate relevant dual practice regulations (eg, prescribing the floor level of physicians' working hours in public hospitals) and design appropriate regulatory measures (eg, ensuring the highest income limits for physicians in private hospitals and conducting regular performance evaluations), guaranteeing health service quality in public hospitals, ensuring patients' medical access, and controlling physicians' illegal income to some extent. Implementation of dual practice and establishment of appropriate regulatory mechanisms (both inspired and supervised measures) are essential in improving the quality and efficiency of health services. ${ }^{6,7}$

In the People's Republic of China, there is uneven distribution of human health care resources (especially highquality resources) between urban and rural areas, hospitals, and community health centers. ${ }^{8}$ The Chinese government established the dual practice policy to promote the flow and improve the efficiency of human resources, and enhance the convenience and accessibility of high-quality medical services. The policy for dual practice was first put forward in the People's Republic of China in 2009; subsequently, pilot activities regarding dual practice appeared. ${ }^{9}$ However, implementation of the dual practice policy was carried out slowly, and of the total number of physicians in Beijing, Zhejiang, and Guangdong, the percentage of physicians involved in dual practice were $5 \%, 3.1 \%$, and $2.4 \%$, respectively. ${ }^{10}$ The reasons for this could be that the regulations for dual practice had not been completed and physicians and patients were unaware of the related knowledge of dual practice. ${ }^{11}$

Previous studies about factors determining physicians' involvement in dual practice include factors related to government (such as regulations in legal and governmental policy), hospital (such as support from health institutions and physicians' practice regulations), medical staff (such as demographic characteristics, family situations, work-related risk, insurance, income, and workload). ${ }^{12-16}$ Physicians who are willing to participate in dual practice are mainly attracted by revenue. ${ }^{17}$ For profit maximization, a high number of physicians shift to private hospitals, which provide higher salaries. Moreover, lassitude in physicians, overdiagnosis and overtreatment of patients, and abuse of public hospitals' resources are common. Physicians' allocation of labor between public and private health institutions to maintain quality in both services, the validity of governmental monitoring mechanisms, and calculation methods to determine regulatory costs are necessary for sustainable development of dual practice..$^{2,18,19}$

Existing studies examining dual practice have focused on establishment of the theoretical framework and description of the current status (involved standards, locations, time and scope of dual practice, dual practice policies, motivation and forces behind dual practice, and consequences of dual practice). ${ }^{14,17,20,21}$ Few have examined the factors influencing people's perception of dual practice, and relevant research about outpatients is lacking. Therefore, this study was conducted to determine the people's current perception of dual practice with respect to two sides: the supply side (ie, medical staff) and demand side (ie, outpatients). The objectives for the medical staff survey were to: 1) observe the current perception of medical staff of dual practice; 2) analyze the differences between demographic characteristics and perception of medical staff; and 3) explore the possible factors influencing the willingness of medical staff to join dual practice. The objectives for the outpatient survey were to: 1) examine the current perception of outpatients of dual practice; and 2) analyze the influence of demographic characteristics on perception of outpatients. Finally, feasible proposals are provided for perfecting dual practice policy.

\section{Methods}

\section{Participants and sampling}

The study sample included medical staff and outpatients from 13 public hospitals in Shanghai. Simple random sampling was used to recruit participants, and the study was conducted for 2 months (from July to September 2013). The inclusion criteria were as follows: age of 18 years and older; ability to speak, read, and write Chinese; and ability to understand and complete questionnaires independently. The study was approved by the Ethics Committee of The Second Military Medical University (approval number: 2013LL058). This study aimed to examine the perception and acceptance of 
medical staff and outpatients of dual practice. All participants were given an explanation of the aims and objectives of the study. The survey was conducted after all respondents' had provided written informed consent. The questionnaire information was only for academic research and did not involve any commercial interests. All personal information was anonymized prior to analysis.

\section{Reliability and validity of the questionnaires}

Two self-administered questionnaires were designed by our research group based on a literature review. The comprehensiveness of the questionnaire content was examined by three relevant specialists. A pilot study (that included 50 medical staff and 50 outpatients) was conducted using data from Changhai Hospital to obtain information regarding the average time required to complete the questionnaires (within 10 minutes) and response rates of $90 \%$ for medical staff and $92 \%$ for outpatients. Construct validity was used to assess the validity of questionnaires (the method used was principal component analysis, with the Kaiser-MeyerOlkin value, Bartlett's test results, and factor loading as the evaluation indexes). Questionnaire reliability was assessed by Cronbach's alpha coefficient.

For the outpatient questionnaire, the Kaiser-Meyer-Olkin value was 0.724, and the results of Bartlett's test were significant (normal approximate $=2,606.602, P<0.001$ ), which indicated that the factorability of the data obtained from the questionnaire was appropriate, and the data were suitable for principal component analysis. Factor loadings got values equal to 0.633 (the complete results of factor loading matrix are shown in Table S1). In addition, Cronbach's alpha for the overall questionnaire was 0.631 , and the standardized Cronbach's alpha was 0.719 , which demonstrated that the questionnaire had good internal consistency.

For the medical staff questionnaire, the Kaiser-MeyerOlkin value was 0.782 , and the results of Bartlett's test were significant (normal approximate $=2,339.749, P<0.001$ ), which indicated appropriate factorability of the data obtained from the questionnaire. Factor loadings got values equal to 0.594 (the complete results of factor loading matrix are shown in Table S2). In addition, Cronbach's alpha for the overall questionnaire was 0.648, and the standardized Cronbach's alpha was 0.727 , which demonstrated that the questionnaire had good internal consistency.

\section{Study procedures and measures}

A total of 1,000 questionnaires (questionnaire 1) were distributed to outpatients; 750 of these were returned; and 694 met eligibility standards (ie, questionnaires that were complete), resulting in a response rate of $69.4 \%(694 / 1,000)$. Similarly, a total of 1,000 questionnaires (questionnaire 2) were distributed to medical staff; 852 of these were returned, and 667 met eligibility standards, resulting in a response rate of $66.7 \%(667 / 1,000)$.

Questionnaire 1 included 15 closed-ended items pertaining to the perception of outpatients of dual practice, classified into four sections. Section 1 included eight items pertaining to demographic characteristics: sex, occupation, age, monthly income, marital status, educational level, self-rated health status, and the burden of health expenditure. Section 2 included two items pertaining to the perception of outpatients regarding dual practice: whether community health institutions advocated dual practice policy in the current community and whether dual practice could reduce difficulty in consulting a doctor. Section 3 included three items pertaining to the perceived benefits of dual practice: whether dual practice could meet patient demand for health convenience, whether dual practice could meet patient demand for treatment of minor illness, and whether dual practice could meet patient demand for treatment of chronic disease. Section 4 included two items pertaining to acceptance of dual practice by outpatients: whether community health services were your first choice for treatment of minor illnesses if community health centers engaged in dual practice, and whether community health services were your first choice for treatment of chronic disease if community health centers engaged in dual practice.

Questionnaire 2 included 12 closed-ended items pertaining to the perception of medical staff of dual practice, classified into three sections. Section 1 included six items pertaining to demographic characteristics: sex, age, educational level, technical position, title, and department. Section 2 included five items pertaining to the perception of dual practice among medical staff: whether hospital administrators advocated dual practice policy in the current workplace, the willingness to join dual practice, whether respondents possessed knowledge of dual practice policy, whether dual practice increased work-related burden, and whether dual practice could reduce difficulty in consulting a doctor. Section 3 included one item pertaining to the importance of four influencing factors of dual practice among medical staff (these included support from the hospital, whether hospitals' human resource management system permitted free flow of medical staff, willingness of medical staff, and existence of a professional dual practice team), which was assessed using a 5-point Likert scale containing the following responses: 1 = very unimportant, $2=$ unimportant, $3=$ general, 
4= important, and 5= very important. (The questionnaires can be found in the Supplementary material).

\section{Statistical methods}

Basic data were double entered into Epidata 3.0 (The EpiData Association, Odense, Denmark) and sorted using Microsoft Excel (Microsoft Corporation, Redmond, WA, USA). First, basic data were entered into contingency tables, in which rows and columns represented grouping and evaluation variables, respectively. Second, various statistical methods were used to determine statistically significant differences in categorical variables. Statistical Package for Social Sciences (Version 17.0; SPSS Inc., Chicago, IL, USA) was used to analyze data. Parametric (chi-square test and Fisher's exact test) and nonparametric tests (Wilcoxon's rank sum test and Spearman's rank correlation analysis) were utilized for comparison between respondents with different demographic characteristics. We performed the chi-square test and Fisher's exact test (which are used for contingency tables when $20 \%$ of cells have an expected count of $<5$ ) to analyze variables with unordered categorical data. We performed nonparametric tests for comparative analysis of responses for the "important levels regarding the influencing factors for dual practice" item, which provided ordinal and nonnormally distributed data. Wilcoxon's rank sum test (for sex, title, and department) was performed according to whether grouping variables belong to unordered categorical data, and Spearman's rank correlation analysis (for age, educational level, and technical position) was performed according to whether grouping variables belong to ordinal data. The twosided significance level was set at 5\%.

Multinomial logistic regression analysis was used to explore the influencing factors for the willingness of medical staff to join dual practice. The corresponding item ("willingness of medical staff to join dual practice") was considered the dependent variable and belonged to the unordered categorical variables (which had three categories: yes, no, not certain), while the remaining eleven factors acted as independent variables. Bivariate analysis was used to select the potential factors related to the willingness of medical staff. Then, the multinomial logistic regression method was utilized to explore the significant predictors of the dependent variable.

\section{Results}

\section{Participants' demographic characteristics}

In the medical staff survey, among the 667 respondents, $55.2 \%$ were male, and approximately half (49.8\%) were aged between 30 and 40 years. The respondents' educational levels were as follows: bachelor and junior college (29.4\%), master (42.6\%), and doctor (25.9\%). A total of $86.8 \%$ of participants had the title of doctor. Most participants held junior (34.2\%) or intermediate $(41.7 \%)$ technical positions. In addition, most participants worked in internal medicine $(42.3 \%)$ or surgical (38.1\%) departments (Table 1).

In the outpatient survey, among the 694 respondents, more than half $(52.0 \%)$ were female, and the proportion of patients aged between 20 and 30 years (34.4\%) was the highest. Respondents' occupations were as follows: retirees $(22.2 \%)$, factory workers $(16.1 \%)$, and students (13.7\%). Regarding income, $28.8 \%$ of the participants earned between 2,001 and 3,000 RMB per month, and $25.6 \%$ earned between 3,001 and 5,000 RMB. The proportions of married and single outpatients were $69.5 \%$ and $25.5 \%$, respectively. Most participants (69.9\%) were

Table I Basic demographic characteristics of medical staff $(\mathrm{N}=667)$

\begin{tabular}{|c|c|c|}
\hline Variables & Number & Percentage \\
\hline \multicolumn{3}{|l|}{ Sex } \\
\hline Male & 368 & 55.2 \\
\hline Female & 299 & 44.8 \\
\hline \multicolumn{3}{|l|}{ Age (years) } \\
\hline $18-20$ & I & 0.1 \\
\hline $20-30$ & 163 & 24.4 \\
\hline $30-40$ & 332 & 49.8 \\
\hline $40-50$ & 140 & 21.0 \\
\hline $50-60$ & 26 & 3.9 \\
\hline$\geq 60$ & 5 & 0.7 \\
\hline \multicolumn{3}{|l|}{ Educational level } \\
\hline Junior college & 7 & I.I \\
\hline Bachelor & 189 & 28.3 \\
\hline Master & 284 & 42.6 \\
\hline Doctor & 173 & 25.9 \\
\hline Others ${ }^{\mathrm{a}}$ & 14 & 2.1 \\
\hline \multicolumn{3}{|l|}{ Title } \\
\hline Hospital leader & 3 & 0.4 \\
\hline Clinical department director & 46 & 6.9 \\
\hline Medical-technical department director & 5 & 0.7 \\
\hline Doctor & 579 & 86.8 \\
\hline Others $^{\mathrm{b}}$ & 34 & 5.2 \\
\hline \multicolumn{3}{|l|}{ Technical position } \\
\hline Junior & 228 & 34.2 \\
\hline Intermediate & 278 & 41.7 \\
\hline Vice senior & 115 & 17.2 \\
\hline Senior & 46 & 6.9 \\
\hline \multicolumn{3}{|l|}{ Department } \\
\hline Surgical department & 254 & 38.1 \\
\hline Internal medicine department & 282 & 42.3 \\
\hline Medical-technical department & 49 & 7.3 \\
\hline Others & 82 & 12.3 \\
\hline
\end{tabular}

Notes: a Others include post-doctorate. ${ }^{\mathrm{b}} \mathrm{O}$ thers include researchers. 
educated below the bachelor's degree level. Additionally, $49.4 \%$ of respondents considered themselves healthy, and $63.4 \%$ considered that the health expenditure was affordable (Table 2).

Table 2 Basic demographic characteristics of outpatients $(\mathrm{N}=694)$

\begin{tabular}{|c|c|c|}
\hline Variables & Number & Percentage \\
\hline \multicolumn{3}{|l|}{ Sex } \\
\hline Male & 333 & 48.0 \\
\hline Female & 361 & 52.0 \\
\hline \multicolumn{3}{|l|}{ Occupation } \\
\hline Student & 95 & 13.7 \\
\hline Factory worker & 112 & 16.1 \\
\hline Farmer & 71 & 10.2 \\
\hline Retiree & 154 & 22.2 \\
\hline Civil servant & 21 & 3.0 \\
\hline Medical personnel & 74 & 10.7 \\
\hline Military personnel & 19 & 2.8 \\
\hline Others ${ }^{\mathrm{a}}$ & 148 & 21.3 \\
\hline \multicolumn{3}{|l|}{ Age (years) } \\
\hline $18-20$ & 17 & 2.5 \\
\hline $20-30$ & 239 & 34.4 \\
\hline $30-40$ & 128 & 18.4 \\
\hline $40-50$ & 91 & 13.1 \\
\hline $50-60$ & 92 & 13.3 \\
\hline$\geq 60$ & 127 & 18.3 \\
\hline \multicolumn{3}{|l|}{ Monthly income ${ }^{b}$ (RMB) } \\
\hline 0 & 110 & 15.9 \\
\hline $\mathrm{I}-2,000$ & 112 & 16.1 \\
\hline $2,00 \mathrm{I}-3,000$ & 200 & 28.8 \\
\hline $3,00 \mathrm{I}-5,000$ & 178 & 25.6 \\
\hline $5,00 \mathrm{I}-8,000$ & 63 & 9.1 \\
\hline $8,001-15,000$ & 21 & 3.0 \\
\hline$|5,00|-50,000$ & 8 & 1.2 \\
\hline$>50,000$ & 2 & 0.3 \\
\hline \multicolumn{3}{|l|}{ Marital status } \\
\hline Single & 177 & 25.5 \\
\hline Married & 482 & 69.5 \\
\hline Widowed & 23 & 3.3 \\
\hline Others & 12 & 1.7 \\
\hline \multicolumn{3}{|l|}{ Educational level } \\
\hline High school diploma or lower & 339 & 48.9 \\
\hline Junior college & 146 & 21.0 \\
\hline Bachelor or higher & 209 & 30.1 \\
\hline \multicolumn{3}{|l|}{ Self-rated health status } \\
\hline Very poor & 26 & 3.8 \\
\hline Poor & 80 & 11.5 \\
\hline Ordinary & 245 & 35.3 \\
\hline Healthy & 255 & 36.7 \\
\hline Very healthy & 88 & 12.7 \\
\hline \multicolumn{3}{|l|}{ Burden of health expenditures } \\
\hline Completely affordable & 99 & 14.3 \\
\hline Affordable & 440 & 63.4 \\
\hline Not affordable & 155 & 22.3 \\
\hline
\end{tabular}

Notes: a Others mean freelancers and unemployed personnel. ${ }^{\text {bRMB, RenMinBi }}$ Yuan. The RMB to US $\$$ exchange rate was 0.162 (based on rates for September $15,2013)$.

\section{The perception of medical staff of dual practice}

The results of the medical staff survey showed that more than half $(63.0 \%)$ of the respondents hoped to implement dual practice; however, only $19.0 \%$ reported that hospital administrators advocated dual practice policy in their current workplaces. The proportion of medical staff members who possessed knowledge about dual practice policy was $23.5 \%$. Although $39.0 \%$ of participants held that dual practice would increase work-related burden, $54.3 \%$ of physicians believed that the implementation of dual practice could reduce difficulty in consulting a doctor (Table 3 ).

Additionally, regarding the importance of four influencing factors of dual practice among medical staff (support from the hospital, whether hospitals' human resource management system permitted free flow of medical staff, willingness of

Table 3 Perception of medical staff of dual practice $(\mathrm{N}=667)$

\begin{tabular}{|c|c|c|}
\hline Items & Option & $\mathbf{N}(\%)$ \\
\hline \multirow[t]{3}{*}{ The willingness to join dual practice } & Yes & $420(63.0)$ \\
\hline & No & $68(10.2)$ \\
\hline & Not certain & $179(26.8)$ \\
\hline Whether hospital administrators & Yes & $127(19.0)$ \\
\hline advocated dual practice policy in & No & $218(32.7)$ \\
\hline your current workplace & Not certain & $322(48.3)$ \\
\hline Whether respondents possessed & Yes & $157(23.5)$ \\
\hline knowledge of dual practice policy & No & $510(76.5)$ \\
\hline Whether dual practice increased & Yes & $260(39.0)$ \\
\hline \multirow[t]{2}{*}{ work-related burden } & No & $217(32.5)$ \\
\hline & Not certain & $190(28.5)$ \\
\hline Whether dual practice could reduce & Yes & $362(54.3)$ \\
\hline \multirow[t]{2}{*}{ difficulty in consulting a doctor } & No & I $35(20.2)$ \\
\hline & Not certain & $170(25.5)$ \\
\hline \multirow[t]{5}{*}{ Support from the hospital } & Very unimportant & $15(2.3)$ \\
\hline & Unimportant & $13(2.0)$ \\
\hline & General & $133(19.9)$ \\
\hline & Important & $163(24.4)$ \\
\hline & Very important & $343(51.4)$ \\
\hline Whether hospitals' human resource & Very unimportant & II (I.6) \\
\hline management system permitted free & Unimportant & $24(3.6)$ \\
\hline \multirow[t]{3}{*}{ flow of medical staff } & General & $127(19.0)$ \\
\hline & Important & $221(33.1)$ \\
\hline & Very important & $284(42.6)$ \\
\hline \multirow[t]{5}{*}{ The willingness of medical staff } & Very unimportant & II (I.6) \\
\hline & Unimportant & $18(2.7)$ \\
\hline & General & I $37(20.5)$ \\
\hline & Important & $235(35.2)$ \\
\hline & Very important & $266(39.9)$ \\
\hline Existence of a professional dual & Very unimportant & $5(0.7)$ \\
\hline \multirow[t]{4}{*}{ practice team } & Unimportant & $17(2.5)$ \\
\hline & General & $132(19.8)$ \\
\hline & Important & $266(39.9)$ \\
\hline & Very important & $247(37.0)$ \\
\hline
\end{tabular}


medical staff, and existence of a professional dual practice team), $51.4 \%$ of the respondents believed that "hospital support" was a very important factor for the implementation of dual practice, $42.6 \%$ stated that "whether hospitals' human resource management system to permitted free flow of medical staff" was a very important factor, 39.9\% considered "the willingness of medical staff to engage in dual practice" very important, and 37.0\% deemed the existence of a professional team to implement dual practice very important (Table 3).

\section{Perception of outpatients of dual practice}

The results of the outpatient survey showed that $44.5 \%$ of the participants believed that the implementation of dual practice policy could reduce difficulty in consulting a doctor. With respect to whether dual practice could fulfill the patients' demand, $45.4 \%, 42.4 \%$, and $53.7 \%$ of respondents believed that dual practice could fulfill their demand for health convenience, treatment for minor illness, and treatment for chronic disease, respectively. Under the premise that community health centers engaged in dual practice, $58.5 \%$ of outpatients reported that community health services were their first choice for treatment of minor illness, while $54.6 \%$ reported that community health services were their first choice for treatment of chronic disease (Table 4).

\section{Difference between demographic characteristics and perception of medical staff of dual practice}

For the term "whether hospital administrators advocate dual practice policy in your current workplace", none of the six demographic characteristics $(P>0.05)$ were significantly associated with the perception of medical staff. Regarding the willingness of medical staff to join dual practice, age $(P<0.001)$, educational level $(P<0.001)$, title $(P=0.018)$, technical position $(P=0.019)$, and department $(P=0.044)$ were influential factors. As shown in Table 5, age, title, technical position, and department influenced whether medical staff possessed knowledge about dual practice policy $(P=0.001$, $P=0.019, P<0.001$, and $P=0.042$, respectively). The relationships between "whether dual practice increases work-related burden" and age $(P=0.044)$ and department $(P=0.003)$ were statistically significant. In addition, differences in age $(P=0.005)$, educational level (0.022), and department (0.032) affected cognition regarding whether dual practice could reduce difficulty in consulting a doctor.

The "importance regarding four influencing factors of dual practice among medical staff' item provided ordinal data, which were analyzed using nonparametric tests. The results of Wilcoxon's rank sum test showed that title and department were significantly associated with the perception of medical staff $(P<0.05)$. The results of Spearman's rank correlation analysis showed that educational level and technical position were positively related to the perception of medical staff $(P<0.05)$.

\section{Difference between demographic characteristics and perception of outpatients of dual practice}

In terms of outpatients, the results of chi-square and Fisher's exact tests showed that, of the eight demographic characteristics, age and educational level were not significantly associated with the outpatients' understanding of dual practice. Regarding patients' acknowledgment of propagation of dual practice in their residential areas, occupation $(P=0.01)$ and the burden of health expenditure $(P=0.001)$ were influential factors. Occupation, monthly income, marital status, and the burden of health expenditure affected the patients' perception of "whether dual practice could reduce difficulty in consulting a doctor" ( $P=0.04, P=0.001, P=0.016$, and $P=0.004$, respectively). In addition, self-rated health status $(P=0.016)$ and the burden of health expenditure $(P=0.001)$ were significant

Table 4 Perception of outpatients of dual practice $(\mathrm{N}=694)$

\begin{tabular}{|c|c|c|c|}
\hline Items & Yes, n (\%) & No, n (\%) & Not certain, $n(\%)$ \\
\hline $\begin{array}{l}\text { Whether community health institutions advocated dual practice policy in your } \\
\text { current community }\end{array}$ & $138(19.9)$ & $83(12.0)$ & $473(68.2)$ \\
\hline Whether dual practice could reduce difficulty in consulting a doctor & $309(44.5)$ & $97(\mid 4.0)$ & $288(4 \mid .5)$ \\
\hline Whether dual practice could meet patient demand for health convenience & $315(45.4)$ & $76(11.0)$ & $303(43.6)$ \\
\hline Whether dual practice could meet patient demand for treatment of minor illness & $294(42.4)$ & $230(33.1)$ & $170(24.5)$ \\
\hline Whether dual practice could meet patient demand for treatment of chronic disease & $373(53.7)$ & $105(15.1)$ & $216(31.1)$ \\
\hline $\begin{array}{l}\text { Whether community health services were your first choice for treatment of minor } \\
\text { illness if community health centers engaged in dual practice }\end{array}$ & $406(58.5)$ & $142(20.5)$ & $146(2 \mid .0)$ \\
\hline $\begin{array}{l}\text { Whether community health services were your first choice for treatment of } \\
\text { chronic disease if community health centers engaged in dual practice }\end{array}$ & $379(54.6)$ & $106(15.3)$ & $209(30.1)$ \\
\hline
\end{tabular}

Note: Data shown as N (\%). 


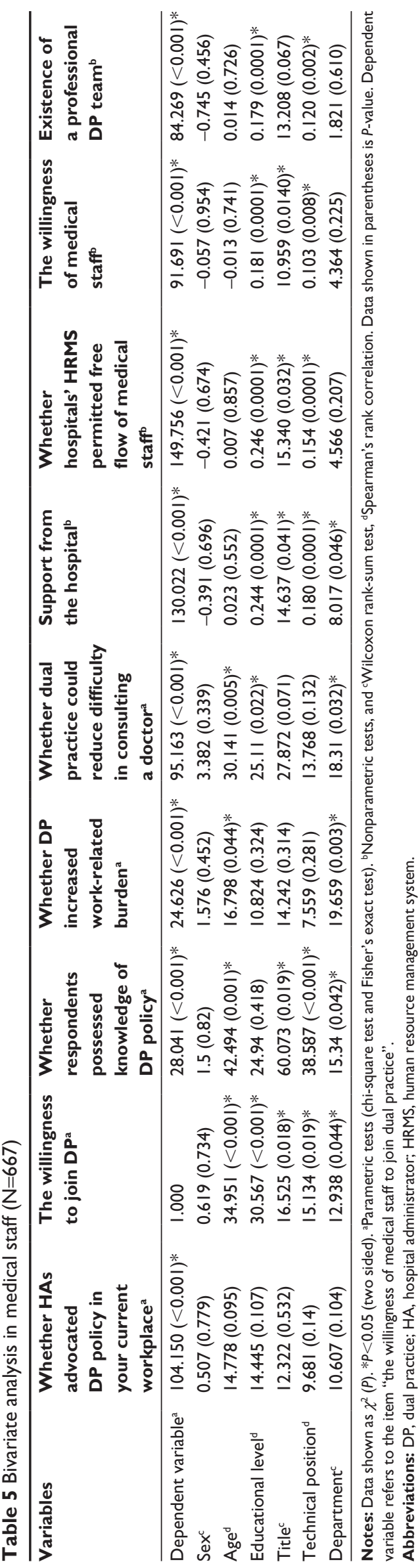

predictors of the patients" perception of "whether dual practice could meet patient demand for health convenience". Of the six demographic characteristics, only the burden of health expenditure was significantly associated with the patients' perception of "whether dual practice could meet patient demand for treatment of minor illness" $(P=0.001)$ and "chronic disease" $(P=0.019)$ and "whether they considered community health services as their first choice for treatment for chronic disease" $(P=0.037)$. Under the premise that community health centers engage in dual practice, differences in age $(P=0.023)$, self-rated health status $(P=0.034)$, and the burden of health expenditure $(P=0.011)$ influenced outpatients' choice of community health services or hospital services for treatment of minor illness (Table 6).

\section{Factors associated with the willingness of medical staff to join dual practice}

Bivariate analysis was used to examine the possible correlations between the dependent variable (willingness of medical staff to join dual practice) and the remaining eleven items. The results indicated that age, educational level, technical position, title, department, whether hospital administrators advocated dual practice policy in the current workplace, whether respondents possessed knowledge of dual practice policy, whether dual practice increased work-related burden, whether dual practice could reduce difficulty in consulting a doctor, and the importance regarding influencing factors for dual practice (a total of ten items) showed significant relationships $(P<0.05)$ with the dependent variable (Table 5$)$. Thus, we selected the ten related items as the response variables for the subsequent analyses.

A multinomial logistic regression method was applied to explore the relationships between the willingness of medical staff to join dual practice and the independent variables. The reference group of the dependent variable consisted of the medical staff who wanted to join dual practice. The likelihood ratio test for model $\chi^{2}=392.251, P<0.001$ indicated that the regression equations were significant. The goodness-of-fit operation showed a good model fit through the following measures: Pearson $\chi^{2}=1,638.172(P<0.001)$, Cox and Snell $R^{2}=0.445$, and Nagelkerke $R^{2}=0.538$.

Comparison was made of medical staff who were uncertain about "the willingness to join dual practice" with medical staff who wanted to join dual practice. According to the outcomes of multinomial logistic regression analysis (Table 7), medical staff who owned a master diploma had lower odds of being uncertain about "the willingness to join dual practice" (odds ratio $[\mathrm{OR}]=0.442,95 \%$ confidence interval $[\mathrm{CI}]=0.233-0.842$; reference: doctor). However, 


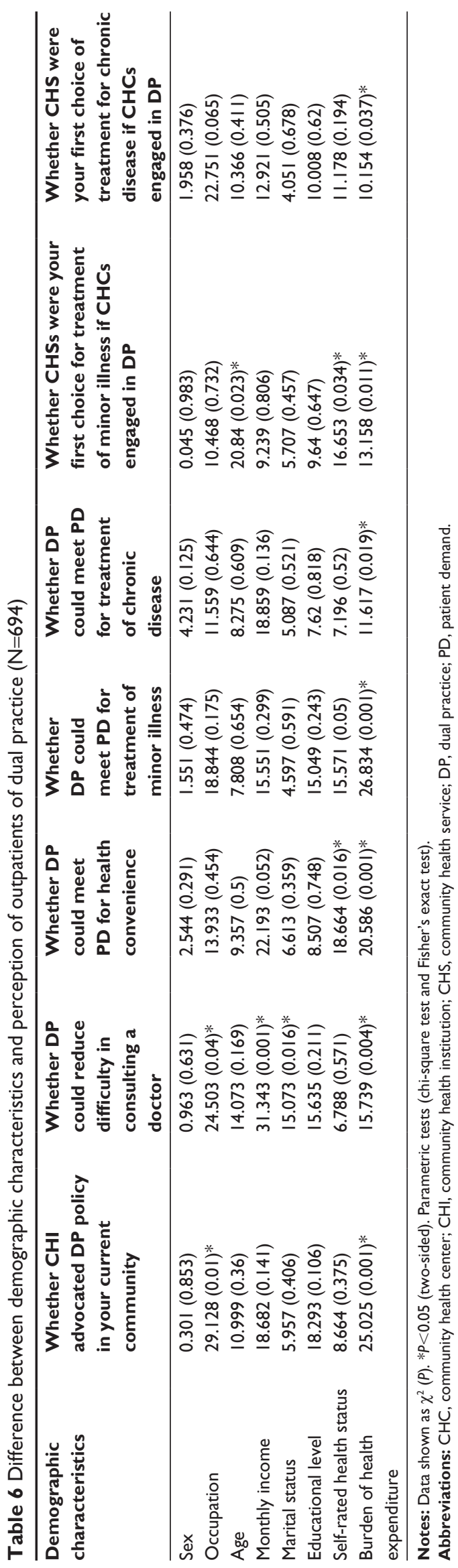

medical staff who were uncertain about "whether hospital administrators advocated dual practice policy in current workplace" ( $\mathrm{OR}=4.308,95 \% \mathrm{CI}=2.066-8.983$; reference: hospital administrators had advocated dual practice policy in current workplace), medical staff who were uncertain about "whether dual practice could reduce difficulty in consulting a doctor" $(\mathrm{OR}=3.820,95 \% \mathrm{CI}=2.189-6.667$; reference: medical staff who held the belief that dual practice could reduce difficulty in consulting a doctor), medical staff who considered "support from the hospital" as a very unimportant or general factor for dual practice (OR $>1$; reference: medical staff who considered "support from the hospital" as a very important factor of dual practice), medical staff who considered "whether hospitals' human resource management system permitted free flow of medical staff" as an important or general factor of dual practice (OR $>1$; reference: medical staff who considered "whether hospitals' human resource management system permitted free flow of medical staff" as a very important factor of dual practice), and medical staff who considered "the willingness of medical staff" as an unimportant factor of dual practice (OR $=9.926,95 \%$ $\mathrm{CI}=1.054-93.456$; reference: medical staff who considered "the willingness of medical staff" as a very important factor of dual practice) all had greater odds of being in the medical staff who were uncertain about "the willingness to join dual practice" group relative to reference group (Table 7).

Medical staff who were opposed to joining dual practice were compared with those who wanted to join dual practice. Medical staff who belonged to the internal medicine department $(\mathrm{OR}=2.206,95 \% \mathrm{CI}=1.027-4.736$; reference: surgical department) and hospital administrators did not advocate dual practice policy in the current workplace $(\mathrm{OR}=3.724$, 95\% CI =1.428-9.710; reference: hospital administrators had advocated dual practice policy in current workplace); medical staff who were uncertain about "whether dual practice could reduce difficulty in consulting a doctor" or held the belief that dual practice could not reduce difficulty in consulting a doctor $(\mathrm{OR}>1$; reference: medical staff who held the belief that dual practice could reduce difficulty in consulting a doctor), and medical staff who considered "whether hospitals' human resource management system permitted free flow of medical staff' as an unimportant or general or important factor for dual practice (OR $>1$; reference: medical staff who considered "whether hospitals' human resource management system permitted free flow of medical staff" as a very important factor for dual practice), all had greater odds of being among medical staff who were opposed to joining the dual practice group compared with the reference group 


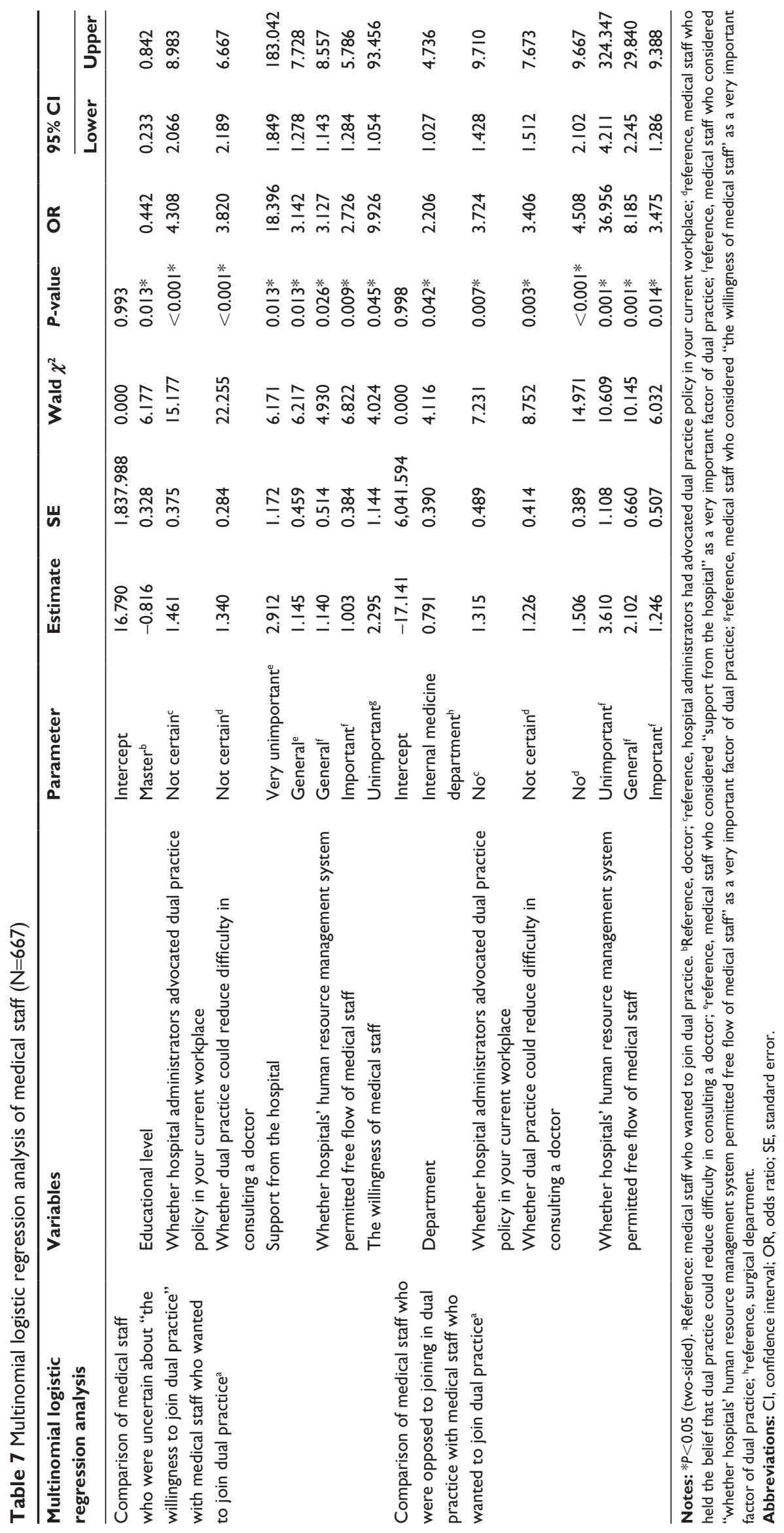


(Table 7). (The completed multinomial logistic regression results are shown in Tables $\mathrm{S} 3$ and $\underline{\mathrm{S}} 4$ ).

In conclusion, medical staff who belonged to the surgical department or held the belief that dual practice could reduce difficulty in consulting a doctor were more willing to participate in dual practice. Moreover, "whether hospital administrators advocated dual practice policy in the current workplace" and "whether hospitals' human resource management system permitted free flow of medical staff" were important factors for dual practice of medical staff.

\section{Discussion}

The study was conducted from the perspectives of supply and demand, and the results showed that both medical staff and outpatients held positive attitudes toward the application of dual practice. Although some physicians believed that the implementation of dual practice would increase workload, a large number of medical staff were willing to engage in dual practice. This finding is similar to those studies conducted by Barros and Olivella, and Iversen, in which medical staff preferred to practice in public and private health institutions simultaneously to obtain the desired benefits. Dual practice policy offers physicians the right to choose practice sites to some extent; physicians divide their time and skills between public and private institutions according to net income maximization, reputation, and work-related burden. ${ }^{22,23}$ As private health institutions provide better remuneration, physicians are more likely to invest time and energy therein, based on the basic principle of labor supply that individuals tend to spend more time in the workplace with the highest income per unit. ${ }^{16,24}$ Therefore, the government should aim to develop more reasonable income ranges for dual practice and select the most appropriate regulatory measures to ensure the quality and safety of health services..$^{18,25-27}$

The outcome of multinomial logistic regression analysis showed that medical staff who belonged to the surgical department or held the belief that dual practice could reduce difficulty in consulting a doctor were more willing to participate in dual practice. These findings are similar to the results of Johannessen and Hagen, who concluded that male surgeons were more likely to engage in dual practice. ${ }^{12}$ In our study, educational levels, technical positions, and support from the hospital were not significantly associated with the willingness of medical staff to join dual practice. However, Jining et al pointed out that opposition by the hospital can block the process of dual practice, ${ }^{14}$ and Gonzalez and McPake et al reported that physicians' professional skills are important in dual practice, physicians with high educational levels and senior technical positions preferred to engage in dual practice. ${ }^{25,28}$ The reason for this could be that these physicians usually have stronger technical expertise and greater clinical experience; therefore, they provide high diagnostic accuracy and have good reputations. In addition, private health institutions prefer to take in human resources with high technology, and remuneration is often linked to reputation. The difference in these two findings is perhaps due to the implementation status of dual practice, which differed according to country and health system. ${ }^{12}$ Therefore, health authorities should consider the effect of various factors when carrying out dual practice policy in medical staff populations.

Moreover, "whether hospital administrators advocated dual practice policy in the current workplace" and "whether hospitals' human resource management system permitted free flow of medical staff" were important factors for dual practice of medical staff. The existence of publicity activities and more flexible management system of hospitals' human resource would promote physicians' willingness to join dual practice. The propaganda of dual practice had significant impact on the willingness of medical staff, and it is necessary for health authorities to carry out comprehensive and positive propaganda solutions. ${ }^{29}$ Additionally, current hospitals' human resource management system of the People's Republic of China imposed restrictions on the sustainable development of dual practice, via improving the relevant management system, more physicians will be allowed to join dual practice. ${ }^{30}$

In outpatients, the application of dual practice helped to satisfy the patient's demand for treatment of minor illness and chronic disease and increased convenience in accessing health services. This is consistent with the results reported by Bir and Eggleston, which indicated that dual practice is beneficial in increasing supply of human health resources, improving health care quality, and enhancing health care availability for patients. ${ }^{13}$ The results of a comparison of the distribution of health workers' educational levels and technical positions between hospitals and community health centers reported in the China Health Statistical Yearbook indicated that the proportions of undergraduates and postgraduates $(34.2 \%)$, and intermediate and senior positions $(34.7 \%)$ in hospitals were higher relative to those observed in community health centers $(20.0 \%$ and $28.2 \%$, respectively). Furthermore, in a comparison of the educational levels and technical positions of physicians and physicians' assistants between hospitals and community health centers, the constituent ratios for undergraduates 
and postgraduates (63.8\%), and intermediate and senior positions $(52.9 \%)$ in hospitals were higher relative to those observed in community health centers $(33.2 \%$ and $39.8 \%$, respectively). ${ }^{31}$ Differences in medical resources and physicians' technical skill levels led patients to seek treatment at large hospitals rather than smaller institutions. ${ }^{32,33}$ Therefore, dual practice in community health centers would increase the number of physicians with high education levels and senior technical positions in the community, which would increase the patients' willingness to attend the centers, reduce the excessive influx of patients to large hospitals, and allow the provision of improved triage services for patients. ${ }^{34}$

There is much discussion regarding the pros and cons of dual practice; some scholars believe that dual practice increases the supply of human health care resources, improves medical care quality, and addresses the issue of overdiagnosis and overtreatment of patients. ${ }^{13,19,34}$ Conversely, there are researchers who posit that the promotion of dual practice could bring adverse effects to public health care providers. First, in the process of dual practice, physicians are driven by profit, as private hospitals offer higher remuneration; thus, many physicians, especially experienced physicians tend to shift from public to private health care institutions, which could decrease the total quantity of physicians and the average medical quality in public institutions. Second, dual practice could affect the physicians' service quality provided by public institutions and their work-hour allocation in public and private institutions, resulting in the phenomenon of moral hazard in physicians, supplierinduced demand, and theft and abuse of public resources by private hospitals. Additionally, the implementation of dual practice policy could bring new challenges to medical quality monitoring, which would increase the management costs of public institutions. ${ }^{15,16,35}$ Although there are both pros and cons to dual practice, there is patient demand for the popularization of dual practice policy, and physicians support the policy and are willing to engage in dual practice; therefore, complete restriction of dual practice is inappropriate. This study examined the perception and acceptance of medical staff and outpatients of dual practice and analyzed the relationships between demographic characteristics and respondents' perceptions of dual practice, to provide information to allow government departments to promote dual practice policy more effectively.

This study was subject to several limitations. First, the study did not examine the family situations of medical staff (such as whether they have a child and the number and ages of children), which could affect physicians' preference for dual practice; future studies should consider physicians' family circumstances. Second, income plays an important role in the willingness of medical staff to engage in dual practice; however, the study did not include examination of medical members' income. Similar studies should focus on the relationship between income level and perception of medical staff. Third, since the participants of this survey were randomly selected, it was not guaranteed that they were familiar with dual practice. Medical staff and outpatients who are acquainted with dual practice possess a deeper understanding of its push and pull factors. Thus, future studies should select participants who are familiar with dual practice to obtain more useful information.

\section{Conclusion}

This study examined the perception of medical staff and outpatients of dual practice, and the results showed that both medical staff and outpatients supported the implementation of dual practice and believed that the policy would reduce difficulty in consulting a doctor. In addition, medical staff who belonged to the surgical department or held the belief that dual practice could reduce difficulty in consulting a doctor were more willing to participate in dual practice. Moreover, the existence of publicity activities and more flexible management system of hospitals' human resource would promote the physicians' willingness to join dual practice. Perception of outpatients of dual practice was affected by occupation, age, monthly income, marital status, self-rated health status, and the burden of health expenditure. Therefore, when formulating dual practice policy, governments and related health care institutions should consider the individual characteristics of medical staff and outpatients and apply corresponding measures to increase medical members' willingness to participate in dual practice.

\section{Acknowledgments}

This project was supported by the Major Program of the National Natural Science Foundation of China (71233008), the National Natural Science Foundation of China (71303248), the National Natural Science Foundation of China (71673291), the Key Program of Health System Important Diseases Research and Development Project of Shanghai (2013ZYJB0006), Training Program of the Major Research Plan of the National Natural Science Foundation of China (91224005), and Major Program of Military Logistic Science and Technology during the Twelfth Five-Year Guideline (AWS12J002). 


\section{Disclosure}

The authors report no conflicts of interest in this work.

\section{References}

1. Ferrinho P, Van Lerberghe W, Fronteira I, Hipólito F, Biscaia A. Dual practice in the health sector: review of the evidence. Hum Resour Health. 2004;2(1): 14 .

2. Biglaiser G, Albert Ma CT. Moonlighting: public service and private practice. RJE. 2007;38(4):1113-1133.

3. Organization WH. Involving private Practitioners in Tuberculosis Control: Issues, Interventions, and Emerging Policy Framework. Geneva: WHO; 2001.

4. Chen LC, Hiebert LG. From Socialism to Private Markets: Vietnam's Health in Rapid Transition. Cambridge, MA: Harvard University; 1994.

5. Smith L. How the poor access health services. DFID Sustainable Livelihoods Seminar, Private Sector and Enterprise Development: Pro-poor Markets and Livelihoods; 2001.

6. García-Prado A, González P. Whom do physicians work for? An analysis of dual practice in the health sector. J Health Polit Policy Law. 2011;36(2):265-294.

7. González P, Macho-Stadler I. A theoretical approach to dual practice regulations in the health sector. $J$ Health Econ. 2013;32(1):66-87.

8. Ministry of Health PsRoC. Health Statistics Yearbook. China: Union Medical University Press; 2013.

9. Qiuqi X, Li X, Lan Y. Insights oil multi-institution practice for physicians of public hospitals. Chin J Hosp Admin. 2011;27(3):164-166.

10. Jianxia X, Kai H, Wei N. Comparison and analysis of dual practice model of China and foreign countries. Henan Med Res. 2015;24(11):59-61.

11. Yuanjin X, Zheng T, Shaoming Z, et al. The public hospital doctors' intention and managers coping of doctors multi-sites practice. Med Philos. 2015;36(11):88-93.

12. Johannessen KA, Hagen TP. Physicians' engagement in dual practices and the effects on labor supply in public hospitals: results from a register-based study. BMC Health Serv Res. 2014;14(1):299.

13. Bir A, Eggleston K. Physician dual practice: access enhancement or demand inducement. Tufts University Department of Economics Working Paper. Medford, MA: 2003;11.

14. Jining L, Yuelong W, Zhiyi D, Wen B, Lida L. Analysis of status and countermeasures of doctor multi-sites practice in Shanghai. Chinese $J$ Health Policy. 2011;4(12):26-31.

15. Sichang H, Ruihua Z, Boxing S, Yu C. Investigation and analysis on the cognitive of physician multi-sited licensed policy. Health Econ Res. 2015;334(2):17-21.

16. Gruen R, Anwar R, Begum T, Killingsworth JR, Normand C. Dual job holding practitioners in Bangladesh: an exploration. Soc Sci Med. 2002;54(2):267-279.

17. Moghri J, Mohammad A, Rashidian A, Sari AA. Physician dual practice: a descriptive mapping review of literature. Iran J Public Health. 2016; 45(3):278
18. García-Prado A, González P. Policy and regulatory responses to dual practice in the health sector. Health Policy. 2007;84(2):142-152.

19. Rickman N, McGuire A. Regulating providers' reimbursement in a mixed market for health care. Scott J Polit Econ. 1999;46(1):53-71.

20. Guosheng Y, Hui-Jun L, Zhiyuan L, Hongzhu Z, Yu L. Investigation of patients' recognition and requirement for doctors' multi-site practice of Beijing. Chinese Hospital Manag. 2014;34(8):20-21.

21. Yun S, Huiqian Z. Analysis of status and countermeasures of traditional doctor multi-sites practice in Shanghai. J Tradit Chinese Med Manag. 2014;22(9):1400-1401.

22. Barros PP, Olivella P. Waiting lists and patient selection. J Econ Manage Strat. 2005;14(3):623-646.

23. Iversen $\mathrm{T}$. The effect of a private sector on the waiting time in a national health service. J Health Econ. 1997;16(4):381-396.

24. Lang K. Does the Human-Capital/Educational-sorting Debate Matter for Development Policy? New York: National Bureau of Economic Research; 1992.

25. Gonzalez P. Should physicians' dual practice be limited? An incentive approach. Health Econ. 2004;13(6):505-524.

26. Ashmore J, Gilson L. Conceptualizing the impacts of dual practice on the retention of public sector specialists-evidence from South Africa. Hum Resour Health. 2015;13(1):3.

27. Mossialos E, Allin S, Davaki K. Analysing the Greek health system: a tale of fragmentation and inertia. Health Econ. 2005;14(S1):S151-S168.

28. McPake B, Russo G, Tseng FM. How do dual practitioners divide their time? The cases of three African capital cities. Soc Sci Med. 2014;122: 113-121.

29. Kaicheng L, Junchang C, Renwen G. Cognitive analysis on physicians' multi-site practice from public hospitals: physician groups. Med Philos. 2014;35(5):60-63.

30. Yongjun L, Fanchao M, Qing H. Multi-game research on registered physician multi-site practice in public hospitals in China. Chinese Health Qual Manag. 2016;23(1):110-113.

31. Ministry of Health PsRoC. China Health Statistical Yearbook 2013. China: Union Medical University Press; 2013.

32. Bozic KJ, Kaufman D, Chan VC, Caminiti S, Lewis C. Factors that influence provider selection for elective total joint arthroplasty. Clin Orthop Relate Res. 2013;471(6):1865-1872.

33. Sick B. Selecting a provider: what factors influence patients' decision making? J Healthc Manag. 2011;56(2):99.

34. Fang X, Jian L. Survey and analysis on opinions of patients for multisite licensed policy of medical doctors. J Clin Exp Med. 2014;13(21): 1813-1815.

35. Hipgrave DB, Hort K. Dual practice by doctors working in South and East Asia: a review of its origins, scope and impact, and the options for regulation. Health Policy Plan. 2014;29(6):703-716.
Patient Preference and Adherence

\section{Publish your work in this journal}

Patient Preference and Adherence is an international, peer-reviewed, open access journal that focuses on the growing importance of patient preference and adherence throughout the therapeutic continuum. Patient satisfaction, acceptability, quality of life, compliance, persistence and their role in developing new therapeutic modalities and compounds to optimize

\section{Dovepress}

clinical outcomes for existing disease states are major areas of interest for the journal. This journal has been accepted for indexing on PubMed Central. The manuscript management system is completely online and includes a very quick and fair peer-review system, which is all easy to use. Visit http://www dovepress.com/testimonials.php to read real quotes from published authors. 